\title{
Vitamin D supply: from sun or pill? - Attitudes and recommendation on vitamin $D$ and impact on sun protection practices among German general practitioners evaluated by the network of dermato-oncologists, Onkoderm e.V.
}

\author{
UWE REINHOLD ${ }^{1}$, THOMAS DIRSCHKA ${ }^{2}$, KLAUS HARTGENS ${ }^{3}$, HERBERT KIRCHESCH ${ }^{4}$, ROLF OSTENDORF ${ }^{5}$, \\ HOLGER PETERING $^{6}$, HANSPETER PRIEUR ${ }^{7}$, GERTRAUD KRÄHN-SENFTLEBEN ${ }^{8}$ and WILLY J. MALAISSE ${ }^{9}$ \\ ${ }^{1}$ Department of Dermatology and Dermatological Oncology, Medical Center Bonn Friedensplatz, Bonn; \\ ${ }^{2}$ Dermatology Practice, Düsseldorf; ${ }^{3}$ Onkoderm e.V. Headquarters, Fürstenwalde/Spree; \\ ${ }^{4}$ Dermatology Practice, Köln; ${ }^{5}$ Dermatology Practice, Mönchengladbach; \\ ${ }^{6}$ Dermatology Practice, Hildesheim; ${ }^{7}$ Dermatology Practice, Duisburg; ${ }^{8}$ Dermatology Practice, Blaubeuren, \\ Germany; ${ }^{9}$ Laboratory of Experimental Hormonology, Brussels Free University, Brussels, Belgium
}

Received June 12,2012; Accepted September 3, 2012

DOI: $10.3892 / \mathrm{ol} .2012 .939$

\begin{abstract}
Recommendations concerning the intake of vitamin $\mathrm{D}$ and/or sunlight exposure in the handling of patients with vitamin $\mathrm{D}$ deficiency remain a matter of debate. The present study of the German network of dermato-oncologists (Onkoderm e.V.) refers to an inquiry conducted among general practitioners on this and related issues. Based on 448 answers provided to 10 distinct questions, the consulted physicians recommended vitamin D intake (94\% replies) and/or exposure to sunlight (63\% replies) in their patients with vitamin D deficiency. An average of approximately 26 min daily unprotected exposure to sunlight at midday in spring and summer was recommended. Nevertheless, $91 \%$ of the physicians considered the use of creams protecting against sunlight to be judicious. However, only $54 \%$ of physicians considered it worthwhile practice to protect oneself intensively against UV radiation. This study indicates evidence of a reduction in sun protection practices. Yet, approximately $25 \%$ of the patients were considered to present vitamin D deficiency and, hence, recommendations to prevent or correct the latter situation should not be ignored. Nevertheless, we consider that there is a need to focus messages regarding sun exposure and for continued sun protection practices. These messages should specifically focus
\end{abstract}

Correspondence to: Professor Willy J. Malaisse, Laboratory of Experimental Hormonology, Université Libre de Bruxelles, 808 Route de Lennik, Brussels B-1070, Belgium

E-mail: malaisse@ulb.ac.be

Key words: vitamin D, sunlight exposure, skin cancer on the vitamin $\mathrm{D}$ issue to ensure that the incidence of skin cancer does not increase.

\section{Introduction}

Current recommendations concerning the respective roles of sun exposure and dietary intake in the supply of vitamin D presently remain a subject of endless debate. No less than 20 studies were recently published on this issue. These deal with items such as: the calculated UV exposure levels for a healthy vitamin D status (1); the high prevalence of vitamin D insufficiency (2); the vitamin D supplement doses and serum 25-hydroxyvitamin $\mathrm{D}$ in the range associated with cancer prevention (3); the knowledge and attitudes concerning vitamin $\mathrm{D}$ and impact of sun protection practices among urban office workers (4); the need for future sun protection campaigns to address the issue of vitamin $\mathrm{D}$ and present strategies to achieve sufficient vitamin D levels in countries with high UV radiation throughout the year (5); the attitudes, practices and knowledge of general practitioners with regard to vitamin D in relation to prescribing sunshine (6); the impact of public health messages in terms of vitamin D and sun protection, as well as protection against skin cancer (7); the hazard of UV radiation for children and adolescents (8); the evaluation, treatment and prevention of vitamin D deficiency considered in a clinical practice guideline (9); the effects of ambient sunlight and photoprotection on vitamin D status (10); the common genetic determinants of vitamin D insufficiency (11); an overview analysis of the time individuals spend outdoors (12); the effectiveness of casual exposure to summer sunlight for maintaining adequate vitamin D status (13); the possible reduction of vitamin D production to insufficient levels resulting from the widespread use of sun creams, particularly those with high sun protection factors (14); the optimal exposure to sunlight 
in order to both maximise vitamin D synthesis and minimise undesirable damages (15); and another position statement on the risks and benefits of sun exposure (16).

In Germany, the matter under consideration was also far from being ignored. The following publications attest, in a far from exhaustive manner, of such a concern. In 2008, Reinhold et al drew attention to the measurements of circulating 25-hydroxyvitamin D concentrations in 97 German cancer patients. The authors proposed that an abnormally low serum $25(\mathrm{OH}) \mathrm{D}$ concentration represents a preferential risk factor, in middle-aged females, for breast cancer, as compared with other neoplastic manifestations in female subjects (17). A report from the Robert Koch-Institute (Berlin, Germany) dealt with several questions concerning vitamin D status (18). The dietary source of vitamin D was first briefly mentioned. The percentage of young (3-17 year-old) and older (18-79 year-old) male and female subjects presenting a severe, moderate or mild deficiency in vitamin $\mathrm{D}$ were also provided with consideration of both seasonal and geographical (for example, subjects with a migration background) differences. Recommendations were offered on both the dietary uptake of vitamin D, according to gender and age, and exposure to UV. For instance, a daily exposure to outside sunshine of 15-20 min between spring and winter with uncovered face and arms was recommended, with care to avoid sunburn. The potential consequences and risks of vitamin D deficiency were also discussed. The correlation between vitamin D status and health was the further theme of a study published in 2008 by Hintzpeter et al (19). Up to $81 \%$ of male subjects and $89 \%$ of female subjects were found to have a $25(\mathrm{OH}) \mathrm{D}$ intake below the recommended level of $5.0 \mu \mathrm{g}$ per day. The seasonal variation in the serum concentration of $25(\mathrm{OH}) \mathrm{D}$ was highlighted. The female subjects aged between 65 and 79 years were considered to have a higher risk of vitamin D deficiency. Lastly, and most importantly, a 'consensus article' was recently published (20). It reflects the opinion of the Ernährungs-kommission der Deutschen Gesellschaft für Kinder und Jugendmedizin (DGKJ) in collaboration with the Arbeitsgemeinschaft Pädiatrische Endokrinologie (APE). It concerns such items as the photoproduction and metabolism of active vitamin D and its biological function in calcium and phosphate homeostasis, as well as in bone mass regulation. It stresses the suboptimal vitamin D status currently prevailing in all age groups. It aims to summarise, from available literature in national and international publications, the reference values for vitamin D supply and consumption. It defines recommendations for infants, children and adolescents living in Germany in order to achieve improved vitamin D status. These recommendations include protected sunlight exposure, intense physical activity (at least one hour daily) outside and increased vitamin D intake via supplements. In these respects, special attention is given to risk groups, including children nourished on a vegetarian diet, migrants, individuals with limited sunlight exposure and chronically ill individuals.

Taking into account these considerations, the main aims of the present study were to present the information recently gained from an inquiry conducted among 448 general practitioners (Hausärzten) and to deal with the issue of vitamin D deficiency.

\section{Materials and methods}

The list of 10 questions submitted to general practitioners working in different regions of Germany is given in Table I. All results are expressed as mean values $( \pm$ SEM). The statistical significance of differences between mean values was assessed by use of a Student's t-test. $\mathrm{P}<0.05$ was considered to indicate a statistically significant result.

\section{Results}

Question 1. As indicated in the addendum and as based on 411 answers (Fig. 1), the consulted physicians considered that, on average, $25 \pm 1 \%$ of their patients suffer from a vitamin D deficiency. Based on 397 out of a total of 448 answers, such a deficiency was estimated as being light in $\sim 54 \pm 2 \%$ of the affected patients, whilst considered as severe in only $\sim 10 \pm 1 \%$ and as intermediate in $\sim 37 \pm 2 \%$ of the affected patients (Table II).

Question 2. The majority of consulted physicians (94.2\%) would recommend the intake of vitamin D preparations. An increase in exposure to sunlight was also considered as appropriate by $63.0 \%$ of the physicians. By contrast, the exposure to artificial sources of radiation was advised by only $1.6 \%$ of the consulted physicians, whilst no specific recommendation was only mentioned by $2.5 \%$. It should be stressed that both the intake of vitamin D and increased exposure to sunlight were mentioned by 264 out of 448 answers (58.9\%).

Question 3. In order to restore a sufficient vitamin D production in patients with a vitamin D deficiency, the unprotected exposure to sunlight (for example, at midday in spring and summer) was recommended for $10 \mathrm{~min}$ in $19.0 \%$ of the provided answers, for $20 \mathrm{~min}$ in $30.5 \%$, for $30 \mathrm{~min}$ in $32.6 \%$, for $40 \mathrm{~min}$ in $6.3 \%$ and for longer in $11.6 \%$ of the answers. An average of 26 min exposure to sunlight emerged from these recommendations. Eight consulted physicians made no recommendation in this respect and were, therefore, not taken into account in the above computation.

Question 4. The majority (91.3\%) of consulted physicians considered in general, i.e. in all subjects, the use of creams protecting against sunlight as judicious, whilst only $4.9 \%$ considered it unnecessary. Of the consulted physicians, $3.8 \%$ did not provide a positive or negative answer to this question.

Question 5. The use of creams protecting against sunlight by the patients with a vitamin $\mathrm{D}$ deficiency was considered to make sense by 353/448 (78.8\%) of consulted physicians, whilst not being considered so by only $12.5 \%$. No opinion was expressed by the remaining $8.7 \%$ of consulted physicians.

Question 6. Consistent with the answer to question 5, only $7.3 \%$ of the consulted physicians would not advise the use of creams protecting against sunlight in their patients with a vitamin $D$ deficiency as it may suppress the synthesis of vitamin D by the skin. The other $92.6 \%$ of consulted physicians would be in favour of the use of these creams in their patients with a vitamin D deficiency. Approximately $30 \%$ of the latter physi- 
Table I. List of 10 questions distributed to general practitioners.

\begin{tabular}{|c|c|c|}
\hline Number & Question & Answers \\
\hline 1 & $\begin{array}{l}\text { How high do you estimate the percentage } \\
\text { of your patients with a vitamin D deficiency } \\
\text { warranting treatment? }\end{array}$ & $\begin{array}{l}\text { A) Light } \\
\text { B) Moderate } \\
\text { C) Severe }\end{array}$ \\
\hline 2 & $\begin{array}{l}\text { What do you advise to your patients with a } \\
\text { vitamin D deficiency? }\end{array}$ & $\begin{array}{l}\text { - Intake of vitamin D preparation } \\
\text { - Increased exposure to sunlight } \\
\text { - Exposure to artificial radiation } \\
\text { - No recommendation }\end{array}$ \\
\hline 3 & $\begin{array}{l}\text { How much direct sunlight exposure do you } \\
\text { believe is adequate to restore sufficient } \\
\text { vitamin D synthesis? }\end{array}$ & $\begin{array}{l}-10 \min \\
-20 \min \\
-30 \min \\
-40 \min \\
- \text { More }\end{array}$ \\
\hline 4 & $\begin{array}{l}\text { How do you judge in general the } \\
\text { recommendation of creams protecting } \\
\text { against sunlight? }\end{array}$ & $\begin{array}{l}\text { - Iudicious } \\
\text { - Unnecessary } \\
\text { - No opinion }\end{array}$ \\
\hline 5 & $\begin{array}{l}\text { How do you judge the recommendation } \\
\text { of creams protecting against sunlight in } \\
\text { your patients with vitamin D deficiency? }\end{array}$ & $\begin{array}{l}\text { - Judicious } \\
\text { - Unnecessary } \\
\text { - No opinion }\end{array}$ \\
\hline 6 & $\begin{array}{l}\text { Do you recommend to your pateints with } \\
\text { vitamin D deficiency the use of creams } \\
\text { protecting against sunlight? }\end{array}$ & $\begin{array}{l}\text { - No, due to the resulting blockade in vitamin D synthesis in } \\
\text { skin } \\
\text { - Yes, all year to prevent light and sun damage to the skin } \\
\text { - Yes, but only in summer to prevent light and sun damage to } \\
\text { the skin }\end{array}$ \\
\hline 7 & $\begin{array}{l}\text { Which measures do you recommend during } \\
\text { winter to your patients with vitamin D } \\
\text { deficiency? }\end{array}$ & $\begin{array}{l}\text { - Intake of vitamin D preparations } \\
\text { - Increased exposure to sunligh } \\
\text { - Whenever possible, travel to more sunny regions to improve } \\
\text { vitamin D status } \\
\text { - Exposure to artificial radiation } \\
\text { - No special recommendation }\end{array}$ \\
\hline 8 & $\begin{array}{l}\text { How do you judge the behaviour of individuals } \\
\text { who protect themselves intensively against } \\
\text { UV radiation by measures such as the use of } \\
\text { anti-light creams or special textiles? }\end{array}$ & $\begin{array}{l}\text { - Judicious } \\
\text { - Limited value due to the risk of vitamin D deficiency } \\
\text { - Advise against this behaviour due to the high risk of } \\
\text { vitamin D deficiency } \\
\text { - No opinion }\end{array}$ \\
\hline 9 & $\begin{array}{l}\text { What would be your opinion on a less strict } \\
\text { protection against UV in order to improve } \\
\text { care of vitamin D status in the population? }\end{array}$ & $\begin{array}{l}\text { - Judicious } \\
\text { - Unnecessary } \\
\text { - No opinion }\end{array}$ \\
\hline 10 & $\begin{array}{l}\text { Which of the following do you have a greater } \\
\text { concern for in your patients in general? }\end{array}$ & $\begin{array}{l}\text { - Skin cancer and sun damage } \\
\text { - Morbid manifestation of vitamin D deficiency } \\
\text { - No opinion }\end{array}$ \\
\hline
\end{tabular}

cians (26.9\% of all physicians) would recommend the use of such creams throughout the year to prevent sunlight damage to the skin. However, the other physicians also providing positive advice ( $65.7 \%$ of all physicians) would restrict the use of such creams in their patients with vitamin D deficiency to the summer period (to prevent sunlight damage to the skin).

Question 7. Question 7 refers to the measures to be adopted during the winter period in patients with a vitamin D deficiency. Five approaches were listed in this question. Up to three of these approaches were, on occasion, considered advisable. In order of decreasing advisability, such approaches entailed: the intake of vitamin D preparations (90.6\% of positive replies); an increased exposure to sunlight (47.0\% of positive replies); whenever possible to travel to sunny regions in order to improve the vitamin D status (17.8\% of positive replies); and the exposure to artificial radiation $(2.4 \%$ of positive replies). Only $3.8 \%$ of the 
Table II. Relative frequency of replies A, B and C to question 1.

\begin{tabular}{|c|c|c|c|c|}
\hline Reported total \% $(\mathrm{A}+\mathrm{B}+\mathrm{C})$ & Number of cases & Reply A (\%) & Reply B (\%) & Reply C (\%) \\
\hline 100 & 32 & $48.3 \pm 5.3$ & $38.4 \pm 5.1$ & $13.2 \pm 2.2$ \\
\hline$>100$ & 5 & $55.6 \pm 5.6$ & $36.5 \pm 5.4$ & $7.9 \pm 2.5$ \\
\hline$\geq 100$ & 37 & $49.3 \pm 4.7$ & $38.2 \pm 4.5$ & $12.5 \pm 2.0$ \\
\hline $1-95$ & 360 & $54.2 \pm 2.0$ & $36.5 \pm 1.9$ & $9.4 \pm 0.9$ \\
\hline All & 397 & $53.7 \pm 1.9$ & $36.7 \pm 1.8$ & $9.7 \pm 0.8$ \\
\hline
\end{tabular}

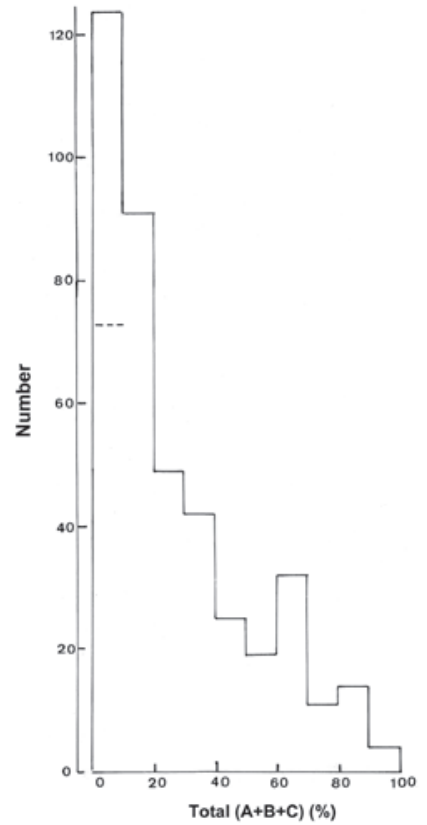

Figure 1. Number of answers to question 1 as a function of the total percentage $(\mathrm{A}+\mathrm{B}+\mathrm{C})$. The dashed horizontal line in the first column to the left separates the number of answers with either a zero (above) or one to nine (below) total percentage $(\mathrm{A}+\mathrm{B}+\mathrm{C})$.

consulted physicians failed to make a recommendation in this respect.

Question 8. Question 8 concerns the consulted physicians' opinions with regard to the behaviour of individuals who protect themselves intensively against UV radiation, by measures such as the use of anti-light creams or special textiles. The majority of physicians $(53.9 \%)$ considered such behaviour as worthwhile. Nevertheless $38.1 \%$ of the physicians considered such behaviour to be of limited value, as it could lead to a vitamin D deficiency. Of the consulted physicians, $4.0 \%$ advised against this behaviour in view of the increased risk of vitamin D deficiency. The remaining $4.7 \%$ of the physicians expressed no opinion on this matter. Incidentally, out of 448 consulted physicians, four provided a dual answer on these questions.

Question 9. The majority of physicians (68.2\%) considered it unnecessary to restrict less severely the protection against UV; for example, by an increase in midday exposure to sunlight. Only $18.9 \%$ of the physicians provided an opposite view, whilst $12.9 \%$ did not express any opinion on this matter.
Question 10. Lastly, $77.3 \%$ of the consulted physicians considered skin cancer and sun damage to be a concern for their patients, whilst only $19.4 \%$ were concerned by the morbid manifestations of vitamin D deficiency. Both concerns were mentioned by $7.8 \%$ of the physicians. No opinion on this matter was formulated by $11.4 \%$ of the consulted physicians.

\section{Discussion}

The mean percentages listed in the Results in answer to the list of 10 questions submitted to the consulted physicians should not mask the considerable dispersion of individual answers in some instances. This is best illustrated in Fig. 1, which depicts the far from negligible variability in assessing the relative number of patients presenting with a vitamin D deficiency (question 1).

With this reservation in mind, another notable finding from the present study is the prevailing concern on skin cancer and sun damage, as distinct from morbid manifestations of vitamin D deficiency (question 10).

In a prevention perspective, the majority of consulted physicians were not in favour of a less strict protection against UV (question 9) and, on the contrary, considered the behaviour of individuals protecting themselves intensively against UV radiation as worthwhile (question 8). However, 54\% of physicians considered the behaviour of individuals who protect themselves intensively against UV radiation to be worthwhile (question 8).

The recommendations for patients with a vitamin D deficiency were mainly in terms of vitamin $\mathrm{D}$ intake and/or an increased exposure to sunlight (question 2). In this respect an average of approximately $26 \mathrm{~min}$ exposure to sunlight emerged from the present inquiry (question 3). This period of sun exposure is associated with a significantly increased risk of severe sun burn in people with certain skin types as well as in most children (21). This result suggests that there is some confusion about the level of sun exposure and vitamin D production that may result in an increased risk of skin damage and skin cancer. During the winter period, emphasis was placed on the intake of vitamin D and, to a lesser extent, to increased exposure to sunlight (question 7). The exposure to artificial sources of radiation was not found advisable, whether in patients with vitamin D deficiency (question 2) or during the winter period (question 7).

Lastly, the use of creams protecting against sunlight was found to be particularly judicious whether in patients with vitamin D deficiency (questions 5 and 6) or in all individuals (question 4).

In conclusion, despite the fact that priority was evidently given to the damaging consequences of uncontrolled sun 
exposure, there remains the need to focus communication regarding this issue specifically on the risk of skin cancer, whilst not ignoring suitable recommendations to prevent or correct vitamin D deficiency.

\section{Acknowledgements}

We are grateful to Mrs. C Demesmaeker for secretarial assistance. We would also like to thank the companies MSD and Meda for their support.

\section{References}

1. Webb AR and Engelsen O: Calculated ultraviolet exposure levels for a healthy vitamin D status. Photochem Photobiol 82: 1697-1703, 2006.

2. van der Mei IA, Ponsoby AL, Engelsen O, Pasco JA, McGrath JJ, Eyles DW, Blizzard L, Dwyer T, Lucas R and Jones G: The high prevalence of vitamin D insufficiency across Australian populations is only partly explained by season and latitude. Environ Health Perspect 115: 1132-1139, 2007.

3. Garland CF, French CB, Baggerly LL and Heaney RP: Vitamin D supplement doses and serum 25-hydroxyvitamin D in the range associated with cancer prevention. Anticancer Res 31: 617-622, 2011.

4. Vu LH, van der Pols JC, Whiteman DC, Kimlin MG and Neale RE: Knowledge and attitudes about vitamin D and impact on sun protection practices among urban office workers in Brisbane, Australia. Cancer Epidemiol Biomarkers Prev 19: $1784-1789,2010$

5. Janda M, Kimlin M, Whiteman D, Aitken J and Neale R: Sun protection and low levels of vitamin D: are people concerned? Cancer Causes Control 18: 1015-1019, 2007.

6. Boneski B, Girgis A, Magin P, Horton G, Brozek I and Armstrong B: Prescribing sunshine: a cross-sectional survey of 500 Australian general practitioners' practices and attitudes about vitamin D. Int J Cancer 130: 2138-2145, 2012.

7. Youl PH, Janda M and Kimlin M: Vitamin D and sun protection: the impact of mixed public health messages in Australia. Int J Cancer 15: 1963-1970, 2009.

8. Balk SJ; Council on Environmental Health; Section on Dermatology: Ultraviolet radiation: a hazard to children and adolescents. Pediatrics 127: 791-817, 2011.

9. Holick MF, Binkley NC, Bischoff-Ferrari HA, Gordon CM, Hanley DA, Heaney RP, Murad H and Weaver CM; Endocrine Society: Evaluation, treatment, and prevention of vitamin D deficiency: an Endocrine Society clinical practice guideline. J Clin Endocrinol Metab 96: 1911-1930, 2011.

10. Diehl JW and Chiu MW: Effects of ambient sunlight and photoprotection on vitamin D status. Dermatol Ther 23: 48-60, 2010.

11. Wang TJ, Zhang F, Richards JB, Kestenbaum B, van Meurs JB Berry D, Kiel DP, Straeten EA, Ohlsson C, Koller DL, et al: Common genetic determinants of vitamin D insufficiency: a genome-wide association study. Lancet 376: 180-188, 2010.

12. Diffey BL: An overview analysis on the time people spend outdoors. Br J Dermatol 164: 848-854, 2011.

13. Diffey BL: Is casual exposure to summer sunlight effective at maintaining adequate vitamin D status? Photodermatol Photoimmunol Photomed 26: 172-176, 2010.

14. Norval M and Wulf HC: Does chronic sunscreen use reduce vitamin D production to insufficient levels? Br J Dermatol 161: 732-736, 2009

15. Webb AR, Kift R, Berry JL and Rhodes LE: The vitamin D debate: translating controlled experiments into reality for human sun exposure times. Photochem Photobiol 87: 741-745, 2011.

16. Callister P, Galtry J and Didham R: The risks and benefits of sun exposure: should skin colour and ethnicity be the main variable for communicating health promotion messages in New Zealand? Ethn Health 16: 57-71, 2011.

17. Reinhold U, Schmitz B, Kurbacher C, Nagel W, Schmidt M and Malaisse WJ: Circulating 25-hydroxyvitamin D concentration in German cancer patients. Oncol Rep 20: 1539-1543, 2008.

18. Hintzpeter B, Mensink GBM, Müller MJ and Scheidt-Nave C: Vitamin D status and health correlates among German adults. Eur J Clin Nutr 62: 1079-1089, 2008.
19. Hintzpeter B, Mensink GBM, Thierfelder W, Müller MJ and Scheidt-Nave C: Vitamin D status and health correlates among German adults. Eur J Clin Nutr 62: 1079-1089, 2008.

20. Wabitsch M, Koletzko B and Moß A: Vitamin-D-Versorgung im Säuglings-, Kindes- und Jugendalter. Monatsschr Kinderheilkd 8: 766-774, 2011 (In German).

21. Pathak MA: Sunscreens: topical and systemic approaches for protection of human skin against harmful effects of solar radiation. J Am Acad Dermatol 7: 285-312, 1982.

\section{Addendum}

The first question appears to have been interpreted differently by the various physicians. Indeed, 37 answers provided a total percentage of either $100 \%$ (32 cases) or more (5 cases with a total percentage of $142 \pm 12 \%$; $\mathrm{P}<0.03$ vs. unity). Considering the distribution pattern for the total percentage, as is subsequently described, it seems evident that these 37 cases included far from negligible answers from physicians who considered that their reply to A, B and C had to reach a total of $100 \%$ (or more). This remark does not intend to deny, however, that, in a limited number of cases, the consulted physicians indeed estimated that all their patients presented a lack of vitamin D. Nevertheless, the vast majority of physicians (411 out of 448 cases, $91.7 \%$ ) provided a total percentage (for $\mathrm{A}+\mathrm{B}+\mathrm{C}$ ) below $100 \%$, implying that they considered all their patients, whether lacking vitamin D or not, as the $100 \%$ total.

In the latter 411 answers, the total percentage $(A+B+C)$ ranged between the extreme values of zero ( 51 cases) and $91 \pm 1 \%$ ( 4 cases). The distribution of the number of replies for each $10 \%$ interval of the total percentage $(A+B+C)$ for these 411 answers is illustrated in Fig. 1. When the zero values for total percentage $(A+B+C)$ were included in the zero to $9 \%$ range, a Poisson-like distribution prevailed, with a progressive decrease in the number of replies for the total percentage $(A+B+C)$. The number of replies decreased from 124 in the zero to $9 \%$ range to 91 replies in the $10-19 \%$ range, $42-49$ replies in the $20-29 \%$ and $30-39 \%$ ranges, $25 \pm 4$ replies in the $40-49 \%, 50-59 \%$ and $60-69 \%$ ranges, $11-14$ replies in the $70-79 \%$ and $80-89 \%$ ranges and only 4 replies in the $90-95 \%$ range. The mean value for total percentage $(\mathrm{A}+\mathrm{B}+\mathrm{C})$ in the 411 answers with individual values below $100 \%$ amounted to $25 \pm 1 \%(n=411)$, suggesting that physicians considered, on average, that approximately one in four patients suffers from vitamin D deficiency.

In order to assess the respective and relative frequency of replies $\mathrm{A}, \mathrm{B}$ and $\mathrm{C}$, the percentages of each of these replies were recalculated (normalized values), assuming a total percentage $(\mathrm{A}+\mathrm{B}+\mathrm{C})$ of $100 \%$ in all cases (i.e. in the 37 answers providing a total percentage of $100 \%$ or more, and in the 360 answers with a total percentage below $100 \%$ but above $0 \%$ ). As documented in Table II, no significant difference in the relative frequency of reply $\mathrm{A}, \mathrm{B}$ or $\mathrm{C}$ was found between the 32 cases with a reported total percentage $(\mathrm{A}+\mathrm{B}+\mathrm{C})$ equal to $100 \%$ and the 5 cases with a reported total percentage above $100 \%$ ( $\mathrm{P}>0.36$ or more). Likewise, no significant difference in the relative frequency (normalized values) of reply $\mathrm{A}, \mathrm{B}$ or $\mathrm{C}$ was found between the 37 cases with a reported total frequency $(A+B+C)$ equal to or above $100 \%$ and the 360 cases with a reported total frequency below 100\% (P>0.25). Pooling together all 397 answers, reply A was more frequent than reply $\mathrm{B}(\mathrm{P}<0.001)$ and reply $\mathrm{B}$ was more frequent than reply $\mathrm{C}(\mathrm{P}<0.001)$. 